\title{
Democracia representativa y democracia deliberativa \\ Un análisis teórico a partir del proceso de reestructuración de las tarifas de gas en Argentina
}

\author{
Ricardo Sebastián Piana 16 \\ Universidad Nacional de la Plata, Argentina \\ r_piana@yahoo.es \\ Gabriela Córdobal7 \\ Universidad Nacional de la Plata, Argentina \\ cordoba.gabriela@gmail.com
}

Fecha de recibido: Noviembre 2016 / Fecha de aprobación: Diciembre 2016

\section{Resumen}

En el presente artículo exponemos la primera crisis del reciente gobierno de Mauricio Macri a partir del fallo de la Corte Suprema de Justicia de la Nación respecto a las políticas de ajuste en las tarifas energéticas. En un contexto de fuerte retraso en el valor las tarifas de los servicios públicos, subsidiadas por el Estado argentino, el aumento fijado por el Ministerio de Energía y Minería a las tarifas del servicio de gas fue judicializado por distintas asociaciones de usuarios por incumplir, principalmente, uno de los postulados más valorados en las actuales políticas de gobierno abierto: la participación ciudadana en las políticas públicas.

Luego de un recorrido teórico que da cuenta del cambio en los últimos años en torno a los valores y presupuestos de la democracia representativa hacia la democracia deliberativa, analizaremos el contexto que dio lugar al aumento de las tarifas, la ausencia de políticas participativas y las consideraciones del fallo de la Corte Suprema de Justicia de la Nación.

Concluimos afirmando que la Audiencia Pública, como mecanismo, no es un mero requisito formal, sino que resulta sustancial para consolidar modelos democráticos en crisis.

\section{Palabras Clave}

\section{Democracia / audiencia pública / representación}

\footnotetext{
${ }^{16} \mathrm{El}$ autor es Doctor en Ciencia Política por la Universidad Nacional de la Plata (UNLP) Argentina

${ }^{17}$ Candidata a Magíster en Maestría y Doctorado en Ciencias Sociales por la Universidad Nacional de la Plata (UNLP) Argentina
} 
In this article we expose the first crisis of the recent government of Mauricio Macri due to the judgment of the Supreme Court of Justice of the Nation regarding the policies of adjustment in energy rates. In a context of depreciated rates of the public services, subsidized by the Argentine State, the increase to the the gas rates ordered by the Ministry of Energy and Mining was prosecuted by different user associations for non-compliance, mainly, one of the most valued postulates in current open government policies: citizen participation in public policies.

After a theoretical development that explains the change in recent years concerning the values and presupposition of the representative democracy towards the deliberative democracy, we will analyze the context that led to the increase of the rates, the absence of participative policies and the considerations of the Ruling of the Supreme Court of Justice of the Nation. We conclude that public hearing, as a mechanism, is not a mere formal requirement, but is substantial to consolidate democratic models in crisis.

\section{Democracy / public hearing / representation}

\section{Tabla de contenido}

I. Introducción. 2. Representación, democracia y deliberación. 3. Sobre la institucionalización de la participación. 4. Los principios jurídicos de la representación y la participación ciudadana en la República Argentina. 5. El inicio del gobierno de Macri y el proceso de aumento de las tarifas. 6. EI fallo de la Corte Suprema de Justicia de la Nación y las audiencias públicas. 7. Las audiencias y su epílogo.

\section{Introducción}

Junto con la expansión del proceso de democratización que se da tanto en Europa como en algunos países latinoamericanos desde la década del ' 80 , se da inicio a una reflexión teórica en torno a la democracia, sus presupuestos y valores subyacentes. A partir de esta coincidencia se ha reactivado el debate sobre las instituciones políticas, las tradiciones liberales y republicanas sus influencias sobre el concepto de democracia.

La democracia es tanto una práctica como un ideal a alcanzar en constante transformación. Muchas de nuestras frustraciones se producen cuando no se distingue la democracia que tenemos respecto de la que deseamos. Interesados en este aspecto, nos proponemos reflexionar sobre las herramientas conceptuales para pensar estas transformaciones y poner en dialogo las perceptivas teóricas que presentan y discuten diferentes concepciones sobre la democracia, centrándonos en la democracia 
representativa y la democracia deliberativa como modelos teóricos aparentemente contrapuestos. Nos preguntamos si estos cambios indican una transformación profunda de las prácticas y normativas de la democracia que dan lugar a nuevos modos de gobierno, o si, por el contrario, no se expresan cambios profundos, sino sólo nuevas formas de legitimar las prácticas ya existentes.

A fin de responder a esas preguntas, sin pretensión de su representatividad, pero convencidos de su relevancia, estudiaremos cómo se dio en Argentina el proceso de reestructuración de las tarifas de gas en el recientemente asumido gobierno de Mauricio Macri. El contexto de un nuevo gobierno que apeló a nuevas prácticas democráticas, la opinión pública favorable al "sinceramiento" de las tarifas, más las urgencias por la recuperación del déficit público, en gran parte producido por los subsidios estatales a la energía, son una combinación perfecta para estudiar, a partir de un caso concreto, los interrogantes teóricos ya planteados.

Iniciaremos el artículo con una reflexión teórica en torno al concepto de representación y a las distintas formas de pensarlo desde la modernidad política. Reflexionaremos sobre distintas propuestas de articulación entre democracia y representación y nos centraremos en las teorías que ponen el foco en la democracia deliberativa por ser las más cuestionadoras a los modelos tradicionales, totalmente deslegitimados en la Argentina desde la crisis política, social y económica que se dio a fines de $200 \mathrm{I}$.

Luego de una breve descripción del contexto bajo el cual asumió la presidencia Mauricio Macri y las políticas de subsidios que a lo largo de más de diez años aplicó el gobierno anterior, describiremos el proceso de aumento de tarifas, especialmente del gas, proceso que derivó en su judicialización hasta llegar a la Corte Suprema de Justicia de la Nación, quien ordenó retrotraer la quieta de subsidios hasta la realización de una audiencia pública al respecto.

\section{Representación, democracia y deliberación.}

Iniciamos nuestro trabajo emprendiendo un breve recorrido para reconstruir teóricamente el concepto de representación para el pensamiento político actual, puesto que se trata de una noción controvertida con múltiples significados a lo largo de la historia. ${ }^{18}$ La importancia de su uso en nuestra problemática se torna central, pues es utilizado como fundamentum divisionis para distinguir la democracia representativa de la deliberativa.

Ya desde comienzos del siglo XX la idea de democracia representativa se ha asociado a tal punto que la relación entre ambos términos, democracia y representación, se nos aparece como inmediatamente

\footnotetext{
${ }^{18}$ Esta problemática se torna aún mayor porque en el debate contemporáneo, el concepto de representación es fuertemente identificado con el de gobierno representativo, llegando a adquirir una enorme popularidad como resultado de su asociación histórica a la democracia.
} 
evidente y a problemática. Sin embargo, los sistemas representativos no son necesariamente democráticos. Así, por ejemplo, Bernard Manin (1995) construye tres tipos ideales de gobierno representativo: el sistema de notables, la democracia de partidos y la democracia de lo público. El primero de ellos, que se identifica con el parlamentarismo clásico anterior a la extensión del sufragio, es representativo pero no una democracia. En otras palabras, la articulación entre democracia y representación no es conceptualmente necesaria sino, por el contrario, absolutamente contingente.

Bobbio (1994) distingue distintas formas de pensar la representación: la delegación, la relación fiduciaria y el espejo sociológico. En el primero el representante es concebido como un ejecutor de las instrucciones que los representados le imparten, de manera que el representante carece de iniciativa propia y de autonomía 19 . En el segundo modelo, la relación fiduciaria, se atribuye al representante una posición de gran autonomía: gobierna a través de como él percibe el interés de sus representados. El último modelo, la representación como espejo o representatividad sociológica, concibe el organismo representativo como un microcosmos que reproduce las características del cuerpo político de manera tal que las características de los representantes reflejan a los representados. A diferencia de los dos primeros modelos, se centra más sobre el aspecto de conjunto que sobre el papel de los representantes individuales. Considerados en su forma pura, ninguno de estos tres modelos se encuentran en las prácticas reales de las democracias representativas contemporáneas pero nos ayudan a identificar esas prácticas como un híbrido que toma elementos de todos ellos.

A su vez nos encontramos con la significativa presencia de teorías que colocan énfasis diferentes sobre los componentes ascendente y descendente que, como señalara Laclau (1993), se hallan siempre presentes en el dispositivo representativo y que condicionan la articulación del elemento representativo con el elemento democrático. En efecto, entre las diferentes teorías de la democracia representativa actualmente en circulación, es posible establecer una clasificación fundada en la forma en que ellas conciben la relación entre democracia y representación ${ }^{20}$.

Robert Dahl (1974; 1987) y Joseph Schumpeter (1966) teóricos ampliamente difundidos, ambos de la corriente pluralista, fijan dos modos polares de entender el mecanismo representativo.

Schumpeter (1966) refuta la teoría clásica de la democracia, según la cual el método democrático sería aquél que realiza el bien común dejando al pueblo decidir las cuestiones en litigio mediante la elección de quienes llevarán a cabo su voluntad. Sostiene que semejante bien común no es posible y que todo lo que hay, en cambio, son enfrentamientos provocados por diferencias irreductibles en los valores últimos.

\footnotetext{
${ }^{19}$ Este modelo es de origen medieval, y no rige en las constituciones modernas, dado que ellas establecen democracias representativas - las cuales, por definición, excluyen el mandato imperativo.

${ }^{20}$ Ahora bien, ¿cuál es la vinculación entre sufragio y régimen representativo? Sin elecciones y, por tanto, sin sufragio, no puede haber régimen representativo propiamente dicho y de ahí que cuán representativo es un régimen depende, en términos generales, de cuán amplia sea su base electoral. A partir de la universalización de la base electoral democracia, elecciones-sufragio y representación conforman la tríada del régimen representativo (al que habrá que agregarle, para cerrar el círculo, la intermediación de los partidos políticos).
} 
Señala, por otra parte, que aun cuando hubiera un bien común aceptable por todos y suficientemente definido, ello no implicaría respuestas igualmente definidas para todos los problemas singulares, lo cual invalida la idea de la existencia de una supuesta voluntad del pueblo. Para Schumpeter el mecanismo democrático se reduce, pues, a la competencia entre dos o más grupos autoseleccionados de dirigentes, en la cual el papel de los votantes no consiste en decidir sobre las cuestiones políticas para luego designar a quienes habrán de ponerlas en práctica sino, más bien, en elegir a los hombres que adoptarán esas decisiones por ellos y en su lugar. Dicho de otro modo: la democracia no es ya pensada como gobierno del pueblo sino como gobierno del político, pues en ella el pueblo sólo tiene la oportunidad de aceptar - rechazar a los hombres que se ofrecen para gobernarlo. Evidentemente, esta concepción de la democracia clausura de entrada todo debate acerca de repensar el tipo de democracia y la "calidad" de ésta.

Para Robert Dahl la democracia es también un procedimiento pero de otra naturaleza: la democracia se caracteriza por su aptitud para responder a las preferencias de los ciudadanos sin establecer diferencias arbitrarias entre ellos (Dahl, 1974) ${ }^{21}$. Para Dahl, hay condiciones necesarias que permiten que se torne posible una democracia: hay requisitos sociales de la democracia, tales como la abundancia material, requisito éste solamente alcanzado en países capitalistas avanzados. De esta abundancia depende que la ciudadanía pueda gozar de ciertos niveles de educación y de información para así poder participar en política. El presupuesto central se condensa en la exigencia del principio de igualdad: los recursos políticos deben ser relativamente iguales para todos los ciudadanos.

Desde otra perspectiva, Laclau (1993) analiza la representación como concepto político "indecidible y constitutivamente impuro"; es el proceso por el cual alguien (el representante) "sustituye" y al mismo tiempo "encarna" al representado: el representante al representar al representado lo constituye y lo modifica. El representado necesita ser representado, porque su identidad básica se encuentra construida en un lugar y las decisiones que afectan su identidad se tomarán, en cambio, en otro lugar. Pero sucede que al estar los representados ausentes del lugar de la representación, su identidad es incompleta, y la relación de representación es un suplemento para la constitución de la identidad. Por lo tanto, la representación es un proceso impuro, que implica un movimiento ascendente, es decir, hay algo que debe ser representado, y un movimiento descendente, movimiento por el cual el representante constituye lo representado. Ambos movimientos son una condición imprescindible de la representación.

Para el estudio de las condiciones actuales de la representación (que será explorado en nuestra investigación para el caso de Argentina) tomamos la distinción analítica que adopta Manin (1995) y que ya hemos reseñado más arriba. Este autor sostiene que las democracias contemporáneas son el producto de la transición de la vieja democracia de partidos a un nuevo formato representativo que recibe el

${ }^{21}$ Dahl prefiere reservar el término democracia para un sistema político ideal, donde exista una perfecta igualdad de poder y prefiere hablar de poliarquías, es decir, el gobierno de muchos, pero no de todos, cuando se está refiriendo a regímenes concretos. 
nombre de "democracia de lo público" y que se caracteriza por la volatilidad electoral, el rol central de una oferta electoral crecientemente personalizada, la desvalorización de los programas partidarios, la mayor independencia relativa de los gobernantes respecto de los gobernados y la existencia de una opinión pública que tiende a constituirse a través de canales relativamente neutros con relación a la escisión entre partidos aunque, ciertamente, más permeables que nunca al poder económico. Dichos rasgos no serían, pues, síntomas de una crisis de la representación sino indicadores de su proceso de metamorfosis.

En las condiciones actuales de la representación, la autonomía de los representantes propia de los sistemas representativos ha tendido a ser considerada crecientemente problemática. En este contexto, numerosos autores han presentado propuestas correctivas o alternativas al problema de la distancia entre representantes y representados, y de la incapacidad de estos últimos para controlar a aquellos.

Entre ellas, seleccionaremos las teorías que giran en torno a la democracia deliberativa pues tienen una mayor radicalidad pues ven en la deliberación un mecanismo alternativo al de la pura y simple votación como dispositivo para la toma de decisiones.

Tomando formulaciones fundamentalmente de Habermas (2005), se considera que la norma tiene legitimidad sólo si se encuentra fundada en razones públicas como resultado de un proceso de deliberación inclusivo y equitativo, proceso en la cual todos los ciudadanos pueden libremente participar y cooperar. El acuerdo intersubjetivo de las discusiones de los ciudadanos en el espacio público es el cimiento de la legitimidad democrática ${ }^{22}$.

Un punto central a destacar es que para esta teoría la voluntad democrática y la razón práctica pueden fusionarse, así como la deliberación institucionalizarse en los procedimientos jurídicos o las instituciones representativas. Como concibe a la sociedad construida sobre una base comunicacional, la legitimidad democrática resulta de la confrontación dialógica y no de la negociación de intereses particulares. En este sentido, tal como señalan Blondiaux y Sintomer (2004), el recurso a la argumentación y a la discusión debería constituir el momento central del proceso político. En esta perspectiva, la legitimidad está dada por el hecho de que todos puedan discutir y ser tenidos en cuenta la pluralidad de los puntos de vista. En este caso, si bien no hay una implicación directa en las decisiones, para la perspectiva deliberativa la representación se iría disolviendo en el ejercicio mismo de la deliberación y de esta manera transformarse en una posible solución para las sociedades marcadas por el pluralismo de valores.

\footnotetext{
${ }^{22}$ En este punto radica la diferencia fundamental con la postura teórica de Manin, porque Habermas ubica el poder constituyente en el espacio público deliberativo fusionando la opinión pública y la deliberación, de manera tal que coloca en el centro de la sociedad política a dicho espacio. A diferencia de Manin, para quien la deliberación es una instancia fundamental y necesaria, pero es una actividad de los representantes, para Habermas la deliberación se sitúa en las discusiones ordinarias de los ciudadanos.
} 
Continuando con el paradigma de la democracia deliberativa, Jon Elster, compilador de un libro titulado Deliberative Democracy define a la democracia deliberativa como la "toma de decisiones mediante la discusión entre ciudadanos libres e iguales" (Elster, 1998:I). Esta perspectiva remite a una concepción integrativa -más que agregativa- de la política, puesto que se centra en la idea de que de lo que se trata es de transformar y constituir las preferencias más que de agregar unas preferencias dada de antemano. La democracia deliberativa es democracia porque el proceso incluye a todos los que serán afectados por la decisión; y es deliberativa porque la toma de decisiones surge del intercambio de argumentos entre participantes apegados a los valores de la racionalidad y la imparcialidad.

\section{Sobre la institucionalización de la participación}

Decíamos más arriba que la deliberación tiende a institucionalizarse. En efecto, tomar decisiones en contextos participativos es complejo, no sólo porque en el ámbito de la intervención política no tenemos posibilidad de predecir el resultado de nuestras acciones, sino también, porque como proceso requiriere organización y coordinación.

Supongamos que debemos tomar una decisión en conjunto. Esa decisión ¿debe surgir por unanimidad, consenso o mayoría, mayorías simples o calificadas? ¿Cómo expresamos esa decisión?, ¿personalmente o por medio de un representante? $Y$ en este último caso, ¿cómo lo elegimos? Y ¿qué representa, mi condición de ciudadano o mi condición socioeconómica o laboral? ¿Es mi participación un derecho, un deber o una obligación? ¿Todos deben expresar su voluntad? Quien no está de acuerdo con una decisión, ¿debe acatarla, siempre? ¿Puede cuestionarse una decisión tomada por la mayoría? Y, en ese caso, ¿quién decide (y toma la decisión final)? ¿Sobre qué temas o problemas podemos debatir? ¿Hay temas, decisiones o leyes sagradas o privilegiadas que no se pueden debatir ni modificar? ¿Se deben proteger a las minorías? $Y$ en ese caso, ¿cómo? ¿Pueden tomarse decisiones en conjunto entre distintos Estados? En caso afirmativo, ¿sobre qué base? Y si la cantidad de electores de uno y otro Estado, son radicalmente distintas, ¿qué hacer?

El orden de las preguntas no es caprichoso: históricamente, como sociedad, hemos ido avanzando, poco a poco, aprendiendo de los errores, generando nuevas preguntas que nos plantean nuevos problemas y retos. Resulta evidente que estas preguntas pueden tener varias respuestas pero no resulta tan evidente que, cualquiera fuese la respuesta, si hemos decidido tomar una decisión en forma participativa también debemos haber acordado en forma previa cómo llegaremos a esa decisión, cuáles son los alcances que podemos darle y qué consecuencias tiene.

Es así que requerimos de ciertas pautas que regulen la participación y es también por ello que la participación en la cosa pública no puede ser equiparada a la acción directa. Ésta, por el contrario, supone que la adopción de medidas concretas e inmediatas de presión, violentas o no violentas, realizadas y auto organizadas por los propios afectados o demandantes, para modificar un estado de situación y que se 
agota en sí misma cuando las demandas son satisfechas o la presión no resulta suficiente. La participación puede ser una práctica natural de una comunidad pero siempre está institucionalizada a través de prácticas, normas y reglas.

Decir que la participación está institucionalizada no quiere decir que deban existir normas jurídicas positivas que regulen esa participación; pero siempre hay normas, formales e informales, que nos guían en el proceso de toma de decisión.

Si las decisiones se toman en forma participativa, todos los actores deben conocer y acatar las mismas reglas de juego. Quien no cumple las reglas, no participa. Pero también quien impone, no hace participar. Si bien no podemos ahondar en este lugar el problema de la libertad, debe quedarnos en claro que la libertad (física, psíquica y emocional) es un componente central del proceso de participación tanto como es un requisito sine qua non para que pueda haber manifestación de nuestra voluntad, una voluntad que no debería ser antojadiza. También en el ámbito público usamos (o debemos usar) nuestra libertad considerando las posibilidades y consecuencias de nuestras acciones. En efecto, libertad en política es ausencia de determinismos; no significa ausencia de condicionantes. Entre esos condicionantes de mis decisiones, está el Otro: en este sentido, actúa políticamente quien coparticipa.

Para casi todos los teóricos clásicos de la democracia, la participación ciudadana ha estado vinculada con la idea de una intensa intervención de los ciudadanos y/o a través de organizaciones intermedias en la iniciativa política o legislativa, esto es, para las grandes decisiones colectivas. Habrá que esperar a que, en el contexto de los estudios sobre Reforma del Estado y de la Administración Pública post Consenso de Washington, recuperada la tesis del Estado como actor central de la política, haga su aparición la idea de participación en la gestión pública como un derecho específico.

Los modelos de democracia representativa resultaron altamente restrictivos a las pretensiones de participación ciudadana. Cerrado el ciclo de las revoluciones liberales, el principio de la soberanía popular fue limitado, por otro lado, por el republicano del "imperio de la ley". La limitación a la participación popular directa fue un patrón en todas las Constituciones liberales ${ }^{23}$. El sufragio aparece como una de las técnicas específicas para la manifestación de la voluntad individual y otro de los institutos, también clásico, es el derecho de peticionar a las autoridades.

El derecho de peticionar a las autoridades, en forma individual o colectiva, aparece como contrapeso de la prohibición de peticionar en nombre del pueblo. El derecho es amplio y por ello la petición siempre procede, aún cuando lo pedido sea improcedente y absurdo. Ello no implica que existe derecho alguno a obtener lo peticionado; debe entenderse que sí existe el derecho a obtener respuesta.

\footnotetext{
${ }^{23}$ Ningún individuo ni grupo particular de individuos tiene, por derecho propio, la facultad de regir a la comunidad, pero ésta, a su vez, carente de concreta e individualizada voluntad propia, sólo se expresa a través de complejas técnicas jurídicas.
} 
En el ámbito normativo, las Constituciones sociales incorporaron la participación ciudadana en forma más amplia a los institutos hasta entonces reconocidos (sufragio; derecho de peticionar a las autoridades). En distintos períodos, pero todas con un denominador común, la necesidad de fortalecer la legitimidad del sistema político, incluyeron institutos de democracia semi-indirecta. Con la democracia semidirecta se produce una coincidencia momentánea, pero directa, entre la titularidad y el ejercicio del poder por parte de la ciudadanía para tomar decisiones políticas o crear normas jurídicas (Cenicacelaya, 2008) ${ }^{24}$. Los pactos internacionales de derechos humanos, también reconocieron el derecho de participación, reproduciendo los esquemas de las constituciones liberales representativas y ampliándolos, previendo la posibilidad de participación directa.

El neoconstitucionalismo latinoamericano, con procesos constituyentes de base popular, amplió aquella base de derechos (Gil Domínguez, 2009). Las Constituciones nuevas como las Nicaragua de 1987, Brasil de 1988, Colombia de 1991, Paraguay de 1992, Perú de 1993, Venezuela de 1999, Ecuador de 2008 y Bolivia de 2009, y menor medida la reforma Argentina de 1994, se enmarcan en este proceso que recupera, por un lado, la existencia de una vinculación entre el derecho y los valores y principios (Alexy, 2010) y por el otro, la necesidad de una recuperación de una función de la jurisdicción creativa y políticamente comprometida (Ferrajoli , 200I; Carbonell, 2003).

El nuevo constitucionalismo latinoamericano, aunque varía de Estado a Estado, tiene como uno de sus puntos comunes, además del reconocimiento del carácter laico y pluricultural del Estado y reconsideraciones sobre la función económica del Estado, la de introducir cambios en los mecanismos de participación ciudadana a través de los institutos de democracia semidirecta y el fortalecimiento de las instancias de control a través del Ministerio Público y las contralorías.

\section{Los principios jurídicos de la representación y la participación ciudadana en la República Argentina}

La República Argentina ha modelado su sistema constitucional y político siguiendo los principios que hemos reseñado más arriba. Definido como un gobierno republicano, representativo y federal, la Constitución argentina de 1853-1860 diseñó un sistema que si bien reconoció su fuente de legitimidad en la soberanía del pueblo (artículo 33), limitó el principio de participación popular. En efecto, a diferencia de la Constitución norteamericana que se tomó como modelo, el Preámbulo de la Constitución argentina invoca al pueblo pero al pueblo representado.

Junto con otros derechos clásicos, como los de trabajar y ejercer toda industria lícita; de navegar y

\footnotetext{
${ }^{24}$ Sus defensores argumentan las decisiones que son, a priori, de superior calidad pues tomadas por el pueblo son, por esencia, más democráticas que las adoptadas por los representantes de éste, gozando de mayor legitimidad. Por otro lado, alientan a los ciudadanos a tener más interés en los asuntos públicos, fomentan la educación política y estimulan la participación popular en la toma decisiones, cuyo proceso se transparenta.
} 
comerciar, profesar libremente su culto; de enseñar y aprender entre otros derechos, el artículo I4 de la Constitución argentina faculta a todos los habitantes de la Nación -y no sólo a sus ciudadanos - a "peticionar a las autoridades". Es cierto que este derecho se encuentra garantizado porque también se resguardan los derechos individuales de asociación con fines útiles; de profesar libremente su culto; de enseñar y aprender pero resulta evidente que es muy limitado y más aún cuando se lo lee junto con el artículo 22 que sigue el postulado de Sieyès:

Artículo 22.- El pueblo no delibera ni gobierna, sino por medio de sus representantes y autoridades creadas por esta Constitución. Toda fuerza armada o reunión de personas que se atribuya los derechos del pueblo y peticione a nombre de éste, comete delito de sedición.

También siguiendo al modelo norteamericano, los constituyentes previeron la participación ciudadana en el Poder Judicial con el establecimiento del juicio por jurados (art. 24, y actuales 75 inc. 12 y I I 8 ) aunque nunca se reglamentó a nivel nacional.

Además, las leyes electorales de nuestra primera época constitucional excluían a las minorías de toda representación. Siguiendo la doctrina de la "pureza del sufragio" o voto calificado, la Ley N I40 de 1857 establecía un voto, exclusivo para los hombres, que era facultativo, personal y no secreto donde, además, los diputados eran elegidos "a simple pluralidad de sufragios". Esto implicaba que allí donde había más de un cargo disponible, dado el esquema plurinominal (comúnmente conocido como de "lista sábana"), el partido que ganaba, aún por un voto, obtenía todos los cargos. Esta ley estuvo vigente hasta 1912, con la sola excepción de las elecciones de 1903 y de 1905, durante las cuales se aplicó el sistema uninominal por circunscripciones, donde se elegía a un solo representante por zona dividiendo así el territorio en tantas circunscripciones cuantos cargos haya a elegir.

Recién con la llamada Ley Sáenz Peña, impulsada por el entonces presidente Roque Sáenz Peña, perteneciente al ala más abierta del Partido Autonomista Nacional (pero también como freno a los antecedentes de las revoluciones de la Unión Cívica primero, en 1890 y de la Unión Cívica Radical después, en 1893 y 1905 , y a los atentados anarquistas y las huelgas obreras) se abrió camino a un sistema de representación de las minorías. La Ley $\mathrm{N}^{\circ} 8.87 \mathrm{I}$ estableció, dentro del esquema plurinominal, el sistema de "lista incompleta", además de fijar el secreto y la obligatoriedad del sufragio. Este mecanismo se llamó de lista incompleta porque el elector sólo podía votar por una lista de candidatos cuyo número fuera equivalente a los dos tercios de los cargos al llenar: la primera mayoría obtenía los dos tercios de los cargos y la primera minoría, el tercio restante.

Lo más destacable de esta Ley, además del mecanismo de representación de las minorías, fue que la obligatoriedad del voto (y la no realización de fraudes como acaeció en la década infame) permitió aumentar fuertemente la legitimidad de los gobiernos electos ${ }^{25}$.

\footnotetext{
${ }^{25}$ A simple modo de ejemplo, mientras Roque Sáenz Peña fue elegido presidente en 1910 con la participación
} 
Sin adentrarnos en las distintas modificaciones que la regulación del sufragio en Argentina ha tenido desde entonces hasta la fecha, siendo sin duda la más importante la inclusión del voto femenino en 1947, resulta relevante destacar que el actual sistema electoral es un sistema de representación proporcional el que tiene como propósito asignar los cargos en los cuerpos representativos de tal modo que su distribución numérica por partidos, listas o tendencias, corresponda matemáticamente a la distribución existente en el cuerpo electoral, es decir, que la composición política del cuerpo elegido refleje con la mayor exactitud posible las preferencias políticas del electorado. Es claro que este mecanismo sólo puede utilizarse para cuerpos políticos donde hay varios miembros para elegir: para la elección del cargo de presidente y vicepresidente no puede ser utilizado. Tampoco se utiliza para la elección de los senadores nacionales como ya veremos más adelante.

Para resumir, desde la reforma constitucional de 1994 y con las actualizaciones al Código Electoral Nacional (sancionado en 1972 pero con muchas modificaciones desde entonces a la fecha), nuestro sufragio tiene las siguientes características: a) el voto es universal; igual; secreto y obligatorio; b) es un sistema de representación proporcional; c) el de D'Hondt es el método matemático que se utiliza para la conversión de votos en escaños; d) sólo se tienen en cuenta los votos de aquellos partidos que superen el umbral 3 \% del padrón electoral de distrito; e) todos los cargos nacionales se eligen en forma directa por los electores (con algunas excepciones, por ejemplo, el Consejo de la Magistratura cuyos representantes son elegidos por los cuerpos a quienes ellos representan; o la Auditoría General de la Nación); f) el Presidente y Vicepresidente se eligen por distrito único con doble vuelta electoral (ballotage) debiendo obtener una porcentaje mayor al $45 \%$ del total de los votos, o bien tener un porcentaje de votos de al menos el $40 \%$ pero con una diferencia porcentual de diez puntos respecto de la fórmula que ocupe el segundo lugar para ser elegidos en primera vuelta o bien a simple mayoría en una nueva elección entre las dos fuerzas políticas más votadas en la primera vuelta electoral; g) los Diputados Nacionales, son elegidos en distritos (cada provincia y la Ciudad Autónoma de Buenos Aires, es un distrito electoral para tal fin) en listas plurinominales según la población de estos distritos de conformidad con las bases del artículo 45 de la Constitución Nacional ${ }^{26}$. La elección se hace, además, a simple pluralidad de sufragios, por listas cerradas y bloqueadas. Es decir, no pueden alterarse los lugares de las listas ni tacharse ni votarse a más de una lista; $h$ ) los Senadores Nacionales se eligen tres por distrito (considerando a las provincias y a la Ciudad Autónoma de Buenos Aires como distritos electorales). Por cada distrito electoral, se eligen tres representantes, dos por el partido que tenga la mayoría y uno por la segunda fuerza más votada.

de sólo 199.000 electores sobre un total de poco más de siete millones de habitantes, seis años más tarde, Hipólito Yrigoyen obtuvo la presidencia en elecciones con la participación de más de un millón de votantes.

${ }^{26}$ Aunque la regla de la cantidad de disputados según la cantidad de electores tiene hoy inequidades porque, por ejemplo, la Provincia de Buenos Aires está sub-representada ya que hay 70 diputados nacionales elegidos en esta Provincia con más de once millones de electores (37,01\% del total) mientras que la Provincia de Tierra del Fuego, con poco más de 125.000 electores ( $0,39 \%$ del total), elige 5 diputados nacionales; y así, para el primer caso se necesiten casi 170.000 votos para un cargo mientras que en el segundo sólo 25.000 votos. 
Pero también decíamos más arriba, la constitución reformada en 1994 introdujo distintos mecanismos de participación que atenuaron los esquemas de democracia representativa. Además de reconocer a los partidos políticos como instituciones fundamentales del sistema democrático (artículo 38) la Constitución introdujo en el artículo 39 el derecho de iniciativa popular para presentar proyectos de ley en la Cámara de Diputados ${ }^{27}$.

Por su parte, el artículo 40 de la Constitución Nacional establece otro instituto de participación, la consulta popular cuando señala que:

El Congreso, a iniciativa de la Cámara de Diputados, podrá someter a consulta popular un proyecto de ley. La ley de convocatoria no podrá ser vetada. El voto afirmativo del proyecto por el pueblo de la Nación lo convertirá en ley y su promulgación será automática.

El Congreso o el presidente de la Nación, dentro de sus respectivas competencias, podrán convocar a consulta popular no vinculante. En este caso el voto no será obligatorio.

El Congreso, con el voto de la mayoría absoluta de la totalidad de los miembros de cada Cámara, reglamentará las materias, procedimientos y oportunidad de la consulta popular.

Fu recién en $200 \mathrm{I}$ cuando, mediante la Ley $\mathrm{N}^{\circ} 25.432$, se reglamentó este mecanismo tanto en su carácter de vinculante como no vinculante.

El artículo 42 de la Constitución Nacional prevé en su segundo y tercer párrafo, aunque sólo en materia de consumidores y usuarios de bienes y servicios que:

Las autoridades proveerán a la protección de esos derechos, a la educación para el consumo, a la defensa de la competencia contra toda forma de distorsión de los mercados, al control de los monopolios naturales y legales, al de la calidad y eficiencia de los servicios públicos, y a la constitución de asociaciones de consumidores y de usuarios.

La legislación establecerá procedimientos eficaces para la prevención y solución de conflictos, y los marcos regulatorios de los servicios públicos de competencia nacional, previendo la necesaria participación de las asociaciones de consumidores y usuarios y de las provincias interesadas, en los organismos de control.

Otras de las menciones hacia la participación que se señalan en nuestra Carta Maga se encuentran entre las atribuciones del Congreso donde se explicita que respecto a los Pueblos indígenas debe asegurarse "su participación en la gestión referida a sus recursos naturales y a los demás intereses que los afecten" y en

${ }^{27}$ Se encuentra regulado por la Ley $\mathrm{N}^{\circ} 24.747$. 
relación a la sanción de leyes de organización y base de la educación del país que las mismas deberán asegurar entre otras consideraciones "la responsabilidad indelegable del Estado, la participación de la familia y la sociedad, la promoción de los valores democráticos y la igualdad de oportunidades y posibilidades sin discriminación alguna..." (Artículo 75 inc. 17 y 19 respectivamente).

Finalmente, y más relevante, es en el artículo 75 inc. 22 de la Constitución la jerarquización a nivel constitucional de ciertos pactos, convenciones y tratados internacionales de derechos humanos, entre ellos, la Declaración Americana de los Derechos y Deberes del Hombre (1948), la Declaración Universal de Derechos Humanos (1948), el Pacto Internacional de Derechos Civiles y Políticos (1966), la Convención Americana sobre Derechos Humanos (1969), la Convención sobre la eliminación de todas las formas de discriminación contra la mujer (1979), la Convención sobre los Derechos del Niño (1989) y la Convención sobre los Derechos de las Personas con Discapacidad (2006). En todos ellos, integrando la Constitución a igual nivel que ésta, aparecen distintos derechos y garantías que protegen la participación ciudadana elevando este derecho a un derecho constitucionalizado, es decir, con la mayor jerarquía normativa dentro de nuestro país.

\section{El inicio del gobierno de Macri y el proceso de aumento de las tarifas}

Tras doce años en la presidencia del matrimonio de Néstor Kirchner y Cristina Fernández de Kirchner (2003-20I5), en diciembre de 2015 el ingeniero Mauricio Macri llega a la presidencia a través de un nuevo espacio político opositor al Frente para la Victoria, el frente Cambiemos. Gana la elección a la Presidencia en el primer balotaje de la historia del país efectivamente realizado obteniendo 12.997 .937 votos que representaron el $51,34 \%$ de los votos positivos emitidos ${ }^{28}$.

El nuevo presidente asume en un contexto de fuerte clivaje político y social que se popularizó en torno al concepto de "la grieta": una división irreconciliable entre los que estaban a favor y los que estaban en contra del gobierno kirchnerista; división que tuvo manifestaciones en los medios de comunicación, en las Universidades, en los ámbitos laborales y aún en las relaciones familiares.

A pocos días de asumir la presidencia, el nuevo gobierno cumplió con algunas de las promesas de campaña que giraban en torno a la idea de "normalizar" el país: en diciembre de 2015 se eliminaron las retenciones a las exportaciones de trigo, maíz, sorgo y carne, en tanto que se redujeron las retenciones a la soja al 30 \%, con un costo fiscal de 23.604 millones de pesos, lo que impactó en el precio de los alimentos, generando fuerte incrementos en productos de primera necesidad. Conjuntamente con estas medidas, se levantaron los controles de cambio, medida que permitió que se aumenten las exportaciones,

${ }^{28}$ El 25 de octubre de 2015, se desarrolla la primera vuelta de la elección presidencial dejando al candidato oficialista Daniel Scioli (FPV) en primer lugar con el 37,08\% de votos, y Macri en segundo lugar con el $34,15 \%$. Los porcentajes obtenidos dieron lugar a una segunda vuelta, casi un mes después, el 22 de noviembre. En esa oportunidad, el macrismo triunfó sobre Scioli, quien obtuvo el 48,66 \%. 
sin que se dispare la cotización del peso argentino. También se acordó pagar a un grupo de holdouts que no habiendo acordado la reestructuración de la deuda propiciada por el gobierno anterior, inició juicio contra el Estado argentino por falta de pago embargando sus cuentas y bienes en todo el mundo. Todas estas medidas, tomadas dentro de los primeros 100 días de gobierno, contaron con altos porcentajes de aprobación y derivaron en una imagen positiva de la gestión del 54 \%, a pesar de generar perjuicios en materia de pérdida salarial de los trabajadores.

Encuadrado esta misma política de "normalización” del país, a pocos días de asumir, el ministro de Energía y Minería Juan José Aranguren ${ }^{29}$, señaló que el Gobierno nacional pondría en marcha un proceso de modificación gradual de los subsidios a las tarifas de los servicios eléctricos y de gas natural que implicaría el "sinceramiento" de las tarifas energéticas.

Al momento de asumir Mauricio Macri los subsidios a la energía durante los últimos diez años habían acumulado 85.000 millones de dólares, llegando a representar en 2015 el 61 por ciento del total de las subvenciones del Estado a la economía. Los valores de las tarifas, congeladas durante casi todo el interregno de gobierno del matrimonio de Néstor Kirchner y Cristina Fernández de Kirchner, se encontraban tan desfasadas que equivalían a sólo $1 / 6$ del promedio regional ${ }^{30}$. Este esquema fue uno de los principales factores del déficit público: estas transferencias representaron alrededor del 3\% del PBI; el $7 \%$ del gasto público o el $61 \%$ del total de subsidios asignados por el Estado en 20I5, cuando diez años antes tales proporciones eran del 0,1\%; 0,8\%; y $4 \%$, respectivamente. ${ }^{31}$

Esta política implicó también un fuerte desincentivo a la inversión de las empresas concesionarias de los servicios públicos, generando inconvenientes en su prestación, especialmente en la calidad del servicio eléctrico cuya infraestructura no pudo atender el crecimiento económico durante el kirchnerismo.

El retraso de las tarifas era un problema reconocido ya durante el inicio del segundo mandato de Cristina Fernández de Kirchner. Se pretendió iniciar una política de "sintonía fina" buscando direccionar los subsidios a los más necesitados ya que aquellos estaban principalmente localizados en la zona metropolitana del Gran Buenos Aires donde conviven las clases pudientes y las más pobres del país. Sin embargo, la política fue errática: a inicios $201 \mathrm{I}$ se promovieron quitas a los subsidios de los servicios

${ }^{29}$ Como otros Ministros del gobierno nacional pasó sin escalas de la gestión privada a la gestión pública tras ser CEO de la operación local de Shell entre 2003 y 2015.

${ }^{30}$ Hasta entonces los usuarios venían pagando 1,29 dólares de los 4,72 dólares que perciben las petroleras por millón de BTU y el resto lo subsidiaba el Estado, pero con el nuevo cuadro tarifario el usuario abonaría 3,42 dólares. Por ello, el Ministro de Energía y Minería sostenía a la prensa que el aumento era gradual. El Estado además cubría la diferencia entre el costo de importación y lo que pagan los usuarios por el gas importado que consumen, que representaba el $26 \%$ del total de la demanda nacional. El precio de la energía importada es en promedio mayor a esos 4,72 dólares que percibía el productor local.

31 https://assets.kpmg.com/content/dam/kpmg/xx/pdf/2016/08/KPMG-Tarifas-Electricas-Mayo2016.pdf

Acceso el 27/10/2016 
públicos de gas, electricidad y agua en los barrios y zonas residenciales de la ciudad de Buenos Aires y el área metropolitana y también se restringieron los subsidios a countries y barrios privados. Para otras zonas se creó, en noviembre de ese mismo año, un registro voluntario para que los usuarios renuncien a esos beneficios, política que fracasó por la poca cantidad de inscriptos. En diciembre de 20 I I se anunció una ampliación en el recorte de subsidios, política que fue suspendida en marzo de 2012 por el fuerte reclamo social contrario y ante el freno del crecimiento económico.

El verano austral 2015-2016, los cortes de energía eléctricos en el área metropolitana del Gran Buenos Aires fueron identificados por el nuevo gobierno como un síntoma de la desinversión en materia energética. Fue en este contexto que se iniciaron las políticas de recortes o "reordenamiento" de subsidios en materia eléctrica. Acorde con los nuevos vientos políticos, un estudio de opinión de febrero de 2016 , señaló que caso el $80 \%$ de los consultados respaldaba el aumento de las tarifas eléctricas ${ }^{32}$.

Ya para esa misma fecha Aranguren adelantaba la necesidad de recortar los subsidios en las tarifas del gas, aunque el "tarifazo" sería inferior a la actualización de los montos de la energía eléctrica33.

Para fines de marzo, por Resolución 34/2016 del Ministerio de Energía y Minería, se anunciaba que los aumentos de la tarifa de gas promediarían el $300 \%$ en todo el país para los hogares aunque se establecían algunos requisitos para una "tarifa social" que según el gobierno alcanzarían a 350.000 familias $^{34}$. Con las nuevas tarifas el Estado ahorraría US\$ 4 mil millones de dólares, mayoritariamente destinados para financiar la importación de gas desde Bolivia y por barco (GNL). Sin embargo, las pequeñas industrias calculaban un aumento superior al $800 \% 35$.

Cuando a mediados de mayo de 2016 llegaron las primeras facturas con las quitas de subsidios, se registraron aumentos de entre 1000 y $2700 \%$ en las facturas del servicio de gas natural en las provincias del sur, las más castigadas por las inclemencias climáticas. Ello derivó en que los gobernadores de las provincias patagónicas iniciaran formales reclamos al gobierno nacional. Un fuerte malestar social derivó en una recolección de firmas contra el aumento e incluso, un amparo en contra del aumento.

Ya para fines de mayo el gobierno, frente a la fuerte presión, dispuso por Resolución 99/2016 del Ministro de Energía y Minería, un tope del $400 \%$ de aumento a las tarifas de gas en los hogares de la Patagonia ${ }^{36}$. Sin embargo, el descontento no cedió y en materia judicial un juez federal de Rawson, Hugo Sastre, hizo lugar al recurso de amparo presentado por el propio gobierno del Chubut y dispuso la no aplicación del incremento tarifario en el

32 http://elinversoronline.com/2016/02/segun-una-encuesta-casi-el-80-de-los-consultados-respalda-elaumento-de-las-tarifas-electricas/

${ }^{33} \mathrm{http}$ // /www.eldestapeweb.com/tras-el-tarifazo-ahora-el-gobierno-analiza-un-aumento-del-gas-similar-alla-luz-n14425

${ }^{34} \mathrm{http}$ // /www.cronista.com/economiapolitica/El-Gobierno-oficializa-hoy-suba-de-gas-que-sera-superior-al300-20160401-0070.html

${ }^{35} \mathrm{http}$ // fortunaweb.com.ar/2016-04-02-176105-los-aumentos-en-el-gas-seran-de-hasta-el-1-700-para-laspequenas-empresas/

${ }^{36}$ Para los comercios y las Pymes, los incrementos de entre el 1.000\% y el 1.500\%, el Gobierno ofrecía la posibilidad de abonar una parte ahora y el otro $50 \%$ en dos cuotas iguales, pagaderas entre octubre de 2016marzo de 2017 y octubre de 2017-marzo de 2018. 
servicio de gas, debido a que no se realizó la audiencia pública y que el aumento "arbitrario y desmedido" afecta a la propiedad privada ${ }^{37} .{ }^{38}$.

Otros amparos habían sido presentados en Bariloche, Santa Cruz y otros lugares. Entre ellos se destaca el presentado por el Centro de Estudios para la Promoción de la Igualdad y la Solidaridad, asociación de usuarios, que había planteado un amparo colectivo en los juzgados federales de la ciudad de La Plata contra la aplicación del nuevo "cuadro tarifario" previsto por la resolución Ministro de Energía y Minería 28/2016, solicitando se suspendiese su aplicación hasta que se garantizara el derecho constitucional a la participación de los usuarios, previsto en el artículo 42 de la Constitución Nacional. A la misma se adhirió luego un particular.

Técnicamente encuadrada como una class action integrada por "todo aquel usuario del servicio de gas, quien no contó con la posibilidad de que sus intereses sean representados con carácter previo al aumento tarifario", se publicitó el amparo colectivo a los fines que otros posibles perjudicaron pudieran presentarse. En ese contexto se adhirió otra asociación de usuarios, Consumidores Argentinos.

A pesar del fuerte descontento por los aumentos, según una consultora de Opinión Pública local, Management \& Fit, un $63 \%$ de los consultados consideró "correcto" que el gobierno nacional haya dispuesto los aumentos de tarifas aunque la gran mayoría de ellos opinó que debería haberse hecho de forma gradual ${ }^{39}$. Solo el $8 \%$ avaló que el incremento se haya dado en una sola vez ${ }^{40}$.

Sin embargo, los procesos judiciales iniciados contra la primera medida continuaron: a inicios de julio de 2016 la Sala II de la Cámara Federal de la ciudad de La Plata, acumulando todas las causas iniciadas, declaró la nulidad de las resoluciones del Ministerio de Energía y Minería de la Nación que autorizaron aumentos en la tarifa de gas y ordenó retrotraer la situación a la fecha previa a la puesta en práctica de esas medidas, argumentando, entre otros fundamentos, que no habían sido precedidas de audiencias públicas.

Para inicios de agosto de 2016, el Gobierno ya había apelado ante la Corte Suprema de Justicia de la Nación. La audiencia a la que fue convocado el Ministro de Energía y Minería por parte de la Cámara de Diputados a mediados de agosto, no logró convencer a la opinión pública ni detener el proceso judicial que para entonces ya estaba bajo análisis por la máxima instancia judicial ${ }^{41}$.

${ }^{37}$ http://www.lanacion.com.ar/1901767-el-gobierno-dispuso-un-tope-del-400-de-aumento-a-las-tarifas-degas-en-la-patagonia. Ver también http://www.pagina12.com.ar/diario/ultimas/20-300859-2016-06-02.html. ${ }^{38} \mathrm{La}$ última audiencia se había realizado en 2005. En esa oportunidad, el llamado no convocó a más de 50 asistentes. En la lista se anotaron 36 oradores y en las cinco horas que duró la audiencia, varios de ellos se rehusaron a hablar. El gobierno que presidía Néstor Kirchner, Metrogas, la Defensoría del Pueblo y los representantes de los usuarios y de los industriales tuvieron la palabra, pero no hubo acuerdo en torno de la renegociación del contrato de distribución de gas natural.

${ }^{39} \mathrm{http}: / /$ www.clarin.com/politica/admite-tarifas-aumentar_0_1622837860.html

${ }^{40}$ Aunque, como hemos reseñado más arriba, el gobierno aún subsidiaba parte de la energía.

41 http://www.infobae.com/politica/2016/08/16/aranguren-expone-ante-diputados-por-el-aumento-de$\underline{\text { tarifas/ }}$ 


\section{El fallo de la Corte Suprema de Justicia de la Nación y las audiencias públicas}

El fallo de la Corte Suprema de Justicia de la Nación "Centro de Estudios para la Promoción de la Igualdad y la Solidaridad y otros el Ministerio de Energía y Minería s/amparo colectivo" se dictó el 18 de agosto de 2016. Además de los requisitos formales para el tratamiento de la causa, la Corte destacó "la trascendencia institucional que exhibe el conflicto a que han dado lugar las resoluciones mencionadas, generando una litigación de características excepcionales que compromete principios básicos del debido proceso constitucional en la tutela de los derechos de los usuarios y del Estado Nacional”2

El eje del debate giró en torno a la necesidad de la audiencia previa al aumento de las tarifas. Luego de resaltar el texto del art. 42 de la Constitución Nacional, la Corte recurrió a los debates de la Convención Constituyente de 1994 que incorporó dicho artículo donde se dijo que este derecho reconoce en esta materia la participación ciudadana en la toma de decisiones públicas con un contenido amplio, traduciendo una faceta del control social que puede manifestarse de maneras distintas. Además recordó que según la Constituyente este nuevo derecho resulta operativo pues su obligatoriedad inmediata no está condicionada a actuación reglamentaria ulterior del Congreso de la Nación, aún cuando éste pueda determinar las circunstancias de los diversos procedimientos y situaciones bajo los cuales tendría lugar el nuevo derecho consagrado expresamente en favor de los usuarios. Por otra parte, este derecho nace -razona la Corte- ante el reconocimiento de las hondas desigualdades y asimetría real inmanentes al mercado y al consumo. Así afirma:

Con particular referencia a la cláusula constitucional cuyo alcance se encuentra discutido en el sub lite, el reconocimiento de que deben habilitarse procedimientos y mecanismos de participación y de impugnación en cabeza de los usuarios tiene el inocultable fin de que sus intereses sean debidamente tutelados.

A fin de resaltar la naturaleza sustancial y no meramente formal de la participación de los usuarios de un servicio público en materia tarifaria, el Máximo Tribunal señala que el requisito no se satisface con la mera notificación de una tarifa ya establecida sino que el deber constitucional es garantizar la participación ciudadana en instancias públicas de discusión y debate susceptibles de ser ponderadas por la autoridad de aplicación al momento de la fijación del precio del servicio.

Para el caso específico del gas la Corte recordó que en 1992, en su ley regulatoria, la participación se estructuró mediante el mecanismo de audiencias públicas, como una de las distintas maneras de participación ciudadana en la toma de decisiones públicas. Y agregó:

\footnotetext{
${ }^{42}$ http://www.cij.gov.ar/nota-22759-Tarifa-de-gas--por-unanimidad--la-Corte-anul--el-aumento-respecto-delos-usuarios-residenciales.html
} 
La participación de los usuarios con carácter previo a la determinación de la tarifa constituye un factor de previsibilidad, integrativo del derecho constitucional a una información "adecuada y veraz" (artículo 42, Constitución Nacional) y un elemento de legitimidad para el poder administrador, responsable en el caso de garantizar el derecho a la información pública, estrechamente vinculado al sistema republicano de gobierno (artículo 10, Constitución Nacional) Asimismo, otorga una garantía de razonabilidad para el usuario y disminuye las estadísticas de litigación judicial sobre las medidas que se adoptan.

Y citando a John Rawls (200I), la Corte señaló que esta forma participativa es consistente con la noción de democracia deliberativa, porque los términos de la cooperación que propone son concebidos como razones que los ciudadanos o sus representantes responsables se dan recíprocamente en un continuado proceso de justificación mutua: el debate público mejora la legitimidad de las decisiones al requerir criterios comprensivos de las distintas posiciones para arribar a un consenso entrecruzado, que permitirá vivir en una sociedad ordenada sobre la base de un criterio más realista de justicia.

En cuanto al fondo del asunto, la Corte recordó que la audiencia siempre se debe hacer para el transporte y distribución de gas, porque son fijados monopólicamente (conf. Ley 24.076) y si bien reconoció que para el sistema de transporte de gas (PIST), no era exigible la realización de audiencia pública por tratarse la producción y comercialización de este recurso de una actividad desregulada, y no fue calificada como servicio público, a partir de lo establecido en el decreto 18I/2004, esa desregulación había sido dejada de lado por el propio Estado, quien para subsidiar a la producción había establecido un sistema de tarifas ${ }^{43}$.

Además, la Corte reconoció que la potestad tarifaria reside en el poder administrador y que ella no se ve afectada por la concesión a particulares de un servicio público. Pero recordó, aplicando una dura crítica a la política del gobierno anterior, que la potestad tarifaria, ý consecuentemente la tarifa, tiene en miras consideraciones de interés público, tales como asegurar la prestación del servicio en condiciones regulares y la protección del usuario: si un régimen tarifario se mantiene inalterado a lo largo del tiempo y la Administración no lo modifica si las circunstancias imponen su modificación, ello implicaría una renuncia ilegítima a esa prerrogativa de control de la evolución de las tarifas que, insistimos, tiene un interés público. $Y$ en este sentido, señaló que la gradualidad en el aumento tarifario es una aplicación concreta del principio de razonabilidad, principio clave para el Estado de Derecho.

\section{Las audiencias y su epílogo}

Tras el fallo, el Gobierno reconoció que fue un error no haber convocado a la Audiencia Pública ${ }^{44}$. Ésta fue convocada para los días 12, 13 y 14 de septiembre de 2016. La Audiencia se dispuso a lo largo de

\footnotetext{
${ }^{43}$ Véase lo dicho en la nota 30.

${ }^{44} \mathrm{http}$ ://www.lanacion.com.ar/1929635-german-garavano-admitio-que-fue-un-error-no-haber-convocado-a-
} 
tres días desde las 9 hs. hasta las 24 hs. El Ministro, según surge de los marcos regulatorios, no está obligado a comparecer. Son los entes de control, en este caso, el Ente Nacional Regulador del Gas (Enargas) o quien el Ministerio decida, el encargado de defender la postura oficial. Luego de la convocatoria, se abrió un período para que los usuarios a título individual, las asociaciones de usuarios o cualquier particular interesado se anotasen como orador. Asimismo, las tres jornadas de audiencias podrían ser seguidas por el canal de YouTube.

El primer día de audiencia comenzó a tiempo, y se extendió hasta las 23 hs. Hubo una gran cantidad de oradores, si bien menos de lo que se esperaba, todo transcurrió en un marco ordenado. Abrieron la jornada el ministro de Energía y Minería, Juan José Aranguren, quien señaló que

El Estado Nacional... subsidia aproximadamente el $80 \%$ del consumo de gas, y lo peor es que- lo subsidia justamente también el 40 por ciento de los argentinos que no tiene acceso a la red de gas natural. Los hogares de la Patagonia y de otros sectores del país que están amparados por algunas de las decisiones judiciales del pasado tienen un precio de gas en boca de pozo que es la décima parte del promedio del país ${ }^{45}$.

Continuaron como oradores el Ministro de Energía de Neuquén, el gobernador de la provincia de Río Negro, Alberto Weretilneck, y los representantes de las principales empresas productoras, transportistas y distribuidores, como YPF, Total Austral S.A., Camuzzi Gas Pampeana y Litoral Gas, entre otras. Por último expusieron diferentes defensorías del pueblo y asociaciones de usuarios y consumidores, quienes plantearon, en conjunto, la necesidad de un aumento escalonado, criticaron la conformación de las tarifas y pidieron por una tarifa social más inclusiva y de simple inscripción.

El día sábado fue el turno de Legisladores Nacionales, sindicatos y algunos especialistas. A continuación fue el turno de las asociaciones de usuarios no residenciales como la Unión Industrial Argentina (UIA), la Cámara de Hoteleros, la Unión de Comerciantes, la Federación Argentina de Expendedores de Nafta del Interior (Faeni) y la Cámara de Expendedores de GNC de distintos puntos del país.

Concluyó la jornada con las palabras de autoridades de diferentes localidades del país. Si bien la audiencia se prolongó hasta las 22 hs., algunas personalidades políticas que se habían anotado como oradores los días previos, y que habían sido parte de debates públicos en los medios de comunicación respecto al tema, en particular aquellos

audiencia-publica-antes

${ }^{45}$ Continuando con su exposición, el Ministro expuso el nuevo cuadro tarifario, expresando que "queremos ir a un sistema en el cual el suministro sea sostenible en el tiempo, promover la producción local, que se reduzcan las importaciones al mínimo necesario, subsidiar solamente a aquellos que lo necesitan, hacer un uso responsable del gas natural y tener un sistema de abastecimiento que sea lo más equitativo y federal posible". Además remarcó la importancia de la tarifa social, orientada a proteger a los más vulnerables, que alcanza a un millón y medio de hogares. Ver http://www.enargas.gov.ar/Publicaciones/AudPub/Informe/Informe\%20Art 21 Res ENARGAS N 31 58 2005.pdf, informe final de la Audiencia Pública. 
que estaban en desacuerdo con el aumento, el día de la audiencia no se presentaron. Por tal motivo, los oradores presentes pudieron extender su tiempo estimado para exponer su posición.

Desde la postura oficial, hubo predisposición para permitir la expresión de todos aquellos que desearan emitir formalmente una opinión pública. Por ese motivo, el Ministerio de Energía y Minería junto al Enargas, emitieron el sábado por la noche un comunicado para alertar a quienes desearan asistir y participar de la última jornada de las Audiencias Públicas ${ }^{46}$. El domingo, última jornada en la que tenían oportunidad de hablar todos aquellos que no lo habían hecho, sólo se presentaron 12 exponentes, y la sesión terminó a media mañana.

Al término de la última jornada, el ministro de Energía y Minería, Juan José Aranguren, que estuvo presente los tres días, brindó una conferencia de prensa en la que destacó que lo que se dijo "será tenido en cuenta". Señaló que en 10 días se presentaría, por parte del Enargas, el informe sobre lo expuesto en las audiencias, y a su vez, deberá dar cuenta de su realización con la publicación en el Boletín Oficial ${ }^{47}$. Asimismo, el Ministro se comprometió a mejorar el proceso participativo donde todos puedan opinar y sugerir, y adelantó que treinta días después de emitido este comunicado, estarán disponibles las nuevas tarifas del gas.

A pesar de las bajas, el saldo que dejó los tres días de sesiones fue positivo: hubo 373 inscriptos como oradores, y más de 300 expusieron su punto de vista. La mayor parte de la participación giró en torno a argumentos políticos, como denuncias, cuestionamientos a los aumentos tarifarios e incluso insultos al gobierno y al propio Ministro que se encontraba presente. En cambio, otras exposiciones se basaron en cuestionamientos y realizaron valiosos aportes desde el punto de vista técnico. Las principales críticas giraron en torno a la falta de información sobre el precio del gas a boca de pozo, la dolarización de las tarifas y las dificultades para acceder a la tarifa social.

Es de destacar las ausencias de personalidades políticas importantes, que los días previos a las audiencias protagonizaron discusiones en los medios de comunicación, y manifestaron su disconformidad públicamente. Faltaron el gobernador de Río Negro, Alberto Weretilneck, quien estaba a cargo de uno de los discursos de apertura; la intendenta de La Matanza, Verónica Magario; el presidente del PJ bonaerense, Fernando Espinoza y los líderes de las CTA, Hugo Yasky y Pablo Micheli.

Otro punto a destacar fue el buen clima que se generó y enmarcó las exposiciones. Aunque el día de la apertura de las audiencias, en el que numerosas agrupaciones políticas y gremiales se agruparon ante las vallas para protestar contra los aumentos, los focos eventuales de conflicto fueron neutralizados. La participación y el interés descendieron con el correr de los días,

\footnotetext{
${ }^{46}$ El comunicado emitido el sábado a la noche lo expresaba de este modo: "El Ministerio de Energía y Minería de la Nación y el Enargas informan que luego de terminar este domingo a la noche el orden del día de la Audiencia Pública para el tratamiento del precio del gas y las tarifas de transporte y distribución, con 420 oradores, el lunes a las 09:00 se abrirán la Usina del Arte y todos los puntos de participación del país para darle una nueva oportunidad de exponer a quienes estaban en el orden del día pero no pudieron presentarse en su debido momento".

${ }^{47} \mathrm{El}$ informe es el que consta en la nota 45.
} 
Es importante destacar, que si bien las audiencias fueron exigidas por un fallo de la Corte Suprema y que no tienen carácter vinculante, tanto el Enargas como el Ministerio, en sus respectivos ámbitos de competencia, debieron fundamentar su resolución final y explicar de qué manera ha tenido en cuenta las opiniones de los participantes de la audiencia.

Si bien la participación y deliberación de todos los ciudadanos no implica que las decisiones que se tomen sean mejores que las discusiones y toma de decisión de los representantes, las audiencias públicas constituyen en sí mismas una práctica participativa ciudadana, un espacio de intercambio de experiencias, conocimientos y opiniones de todas aquellas personas, grupos e instituciones que se vean afectadas 0 sientan interés por el tema. Es a su vez un mecanismo que ayuda a transparentar los actos del gobierno, permite un acceso más igualitario a la información y amplia la participación. En este caso, permitió poner en discusión el cuadro tarifario del gas, fundamentalmente en los medios de comunicación, desde una perspectiva que trascendió las cuestiones auto referenciales y la defensa o la crítica desde posturas partidarias. Es importante destacar que a partir de las audiencias se visibilizó y puso en discusión el estado de la energía en Argentina, la utilización desigual que hay en el territorio, y la ausencia de servicios básicos para una un gran número de ciudadanos.

La audiencia pública, en este caso, ha permitido visibilizar las decisiones políticas, ser cuestionadas, estar sujeta a críticas desde un espacio institucional y fundamentalmente, ha sido un aporte a la importancia de tener que rendir por la toma de decisiones ante los ciudadanos. Sin participación, el verdadero control sería vacío: no resulta la audiencia un requisito formal, sino sustancial. Como lo recordó la corte, el derecho a la participación de usuarios y consumidores se sustenta en el reconocimiento por parte del derecho constitucional argentino de la las hondas desigualdades inmanentes al mercado y al consumo.

Luego de estudiar el presente caso, entendemos que el modelo de democracia deliberativa resulta más bien un modelo ideal, no aplicable en el marco de los grandes procesos estatales. Este paradigma requiere, como hemos visto, procesos públicos apropiados de deliberación integradores de ciudadanos libres e iguales, mientras que en las condiciones modernas, los actuales procesos deliberativos nos muestran actores muy diferenciados en lo económico, político y social, con intereses contrapuestos y de variable intensidad. Justamente, hemos visto cómo el proceso de corrección y aumento de las tarifas del gas se tomó desde una posición política excepcional (el inicio de una gestión) privilegiando las razones económicas (déficit presupuestario) pero sin considerar las variables sociales (gradualidad). Esta falta de equilibrio, criterio de razonabilidad según la Corte argentina, hizo caer el primer aumento de tarifas, en un vaivén de medidas políticas, declaraciones y contradeclaraciones que hicieron tambalear y fracasar una de las primeras políticas del gobierno argentino.

Sin embargo, si a gran escala el modelo deliberativo resulta de imposible práctica, el proceso de la audiencia pública que reseñáramos dio muestras de ser un modelo posible, viable. El marco de conflicto inicial a la audiencia pública se fue desarmando con su desarrollo, lo que da muestras de ser un proceso 
legitimado y legitimador en sí mismo. Este modelo es obviamente aplicable a otros espacios disponibles para la deliberación, desde partidos políticos hasta iniciativas ciudadanas, movimientos sociales, asociaciones voluntarias, grupos de concientización, iglesias y otros.

En Argentina, este tipo de modos de asociación cobran relevancia y surgen como alternativa post crisis de 200I; no para suplir la democracia representativa sino para complementarla y fortalecerla desde sus bases.

\section{Lista de referencias}

Alexy, Robert (2010). La construcción de los derechos fundamentales. Buenos Aires: Ad-Hoc.

Blondiaux, Loîc y Sintomer Yves (2004) "El imperativo deliberativo" en Estudios Políticos № 24, Medellín, enero Junio- de 2004.

Bobbio, Norberto; Matteucci, Nicola y Pasquino, Gianfranco (1994). Diccionario de política. México: Siglo Veintiuno Editores.

Carbonell, Miguel (2003). Neoconstitucionalismo. Madrid: Ed. Trotta.

Cenicacelaya, María de las Nieves (2008). Participación ciudadana. Teoría y práctica de la democracia semidirecta. La Plata: Edulp.

Dahl, Robert (1974). La poliarquía. Participación y Oposición. Madrid: Guadiana Publicaciones.

Dahl, Robert, (1987). Un prefacio a la teoría democrática. México: Ediciones Gernica.

Elster, Jon ed. (1998). Deliberative Democracy. Cambridge: Cambridge University Press.

Ferrajoli, Luigi (200I). Derechos y garantías — La ley del más débil. Madrid: Trotta.

Gil Domínguez, Andrés. (2009). Escritos sobre neoconstitucionalismo. Buenos Aires: Ediar.

Habermas, Jürgen (2005). Facticidad y Validez. Sobre el derecho y el Estado democrático de derecho en términos de teoría del discurso. Madrid: Trotta.

Laclau, Ernesto, (1993) "Poder y Representación”. Revista Sociedad (UBA), nro. 4.

Manin, Bernard (1995) "La democracia de los modernos. Los principios del gobierno representativo". Revista Sociedad N ${ }^{\circ}$ 6, Buenos Aires.

Manin, Bernard, (1992) "Metamorfosis de la representación”, en Mario Do Santos. ¿Qué queda de la representación política?, CLACSO/Nueva Sociedad. Caracas.

Pitkin, Hanna Fenichel, (1985). El concepto de representación. Madrid: Fareso.

Rawls, John, (200I). Justice as Fairness. A restatemen. Harvard: Harvard University Press.

Shumpeter, Joseph A., (1966). Capitalismo, socialismo y democracia. Barcelona: Ediciones Folio.

Tommasi, Mariano, (2008). Un país sin rumbo. Buenos Aires: UdeSA, Mimeo.

\section{Legislación y fallos}

Argentina, Constitución de la Nación Argentina. Disponible en: http://servicios.infoleg.gob.ar/infoleglnternet/anexos/0-4999/804/norma.htm 
Argentina, Congreso de la Nación, Ley $N^{\circ}$ I40, Disponible en: http://www.elecciones.gob.ar/admin/ckfinder/userfiles/files/Ley\%20140-1857.pdf

Argentina, Congreso de la Nación, Ley $\mathrm{N}^{\circ}$ 8.87I, Disponible en: http://www.elecciones.gob.ar/admin/ckfinder/userfiles/files/Ley-887I-Ley-Electoral-S\%C3\%AlenzPe\%C3\%Bla.pdf

Argentina, Congreso de la Nación, Código Electoral Nacional, Ley $\mathrm{N}^{\circ}$ 19.945, Disponible en: http://servicios.infoleg.gob.ar/infolegInternet/anexos/15000-19999/19442/texact.htm

Argentina, Congreso de la Nación, Ley $\mathrm{N}^{\circ}$ 24.076, Disponible en: http://servicios.infoleg.gob.ar/infolegInternet/anexos/0-4999/475/texact.htm

Argentina, Congreso de la Nación, Ley $N^{\circ}$ 24.747, Disponible en: http://servicios.infoleg.gob.ar/infolegInternet/anexos/40000-44999/41025/norma.htm

Argentina, Congreso de la Nación, Ley $N^{\circ}$ 25.432, Disponible en: http://servicios.infoleg.gob.ar/infolegInternet/anexos/65000-69999/675I8/norma.htm

Argentina, Corte Suprema de Justicia de la Nación in re "Centro de Estudios .para la Promoción de la Igualdad y la Solidaridad y otros c/ Ministerio de Energía y Minería s/amparo colectivo”, 20I6. Disponible en: $\quad$ http://www.cij.gov.ar/nota-22759-Tarifa-de-gas--por-unanimidad--la-Corte-anul--el-aumentorespecto-de-los-usuarios-residenciales.html

Argentina, Poder Ejecutivo, Decreto $N^{\circ} \quad 181 / 2004$, Disponible en: http://servicios.infoleg.gob.ar/infolegInternet/anexos/90000-94999/92679/norma.htm

Argentina, Poder Ejecutivo, Ministro de Energía y Minería, Resolución № 28/2016, Disponible en: http://servicios.infoleg.gob.ar/infolegInternet/anexos/255000-259999/259948/norma.htm

Argentina, Poder Ejecutivo, Ministerio de Energía y Minería Resolución Nº 34/2016, Disponible en: http://servicios.infoleg.gob.ar/infolegInternet/anexos/255000-259999/259950/norma.htm

Argentina, Poder Ejecutivo, Ministro de Energía y Minería Resolución N 99/2016, Disponible en: http://servicios.infoleg.gob.ar/infoleglnternet/anexos/260000-264999/262396/norma.htm 